\title{
Ocular surface squamous neoplasia among HIV-infected patients in Botswana
}

\author{
K T Steele, ${ }^{1,2} \mathrm{MD}$; A P Steenhoff, ${ }^{1,2,3,4} \mathrm{MB}$ BCh, DCH, FCPaed (SA); G P Bisson, ${ }^{1,2,5}$ MD, MSCE; O Nkomazana, ${ }^{7,8}$ MD \\ ${ }^{1}$ Perelman School of Medicine at the University of Pennsylvania, Philadelphia, PA, USA \\ ${ }^{2}$ Botswana-University of Pennsylvania Partnership, Gaborone, Botswana \\ ${ }^{3}$ Division of Infectious Diseases, The Children's Hospital of Philadelphia, Philadelphia, PA, USA \\ ${ }^{4}$ Center for AIDS Research, University of Pennsylvania, Philadelphia, PA, USA \\ ${ }^{5}$ Center for Clinical Epidemiology and Biostatistics, Perelman School of Medicine at the University of Pennsylvania, Philadelphia, PA, USA \\ ${ }^{6}$ Division of Infectious Diseases, University of Pennsylvania School of Medicine, Philadelphia, PA, USA \\ ${ }^{7}$ Faculty of Medicine, University of Botswana, Gaborone, Botswana \\ ${ }^{8}$ Princess Marina Hospital, Gaborone, Botswana
}

Corresponding author: O Nkomazana (nkomazanao@mopipi.ub.bw)

\begin{abstract}
Background. Ocular surface squamous neoplasia (OSSN) is a group of ocular tumours that has been rising in incidence among HIVinfected individuals in sub-Saharan Africa. Surgical excision is the mainstay of treatment for OSSN in this region.

Methods. This retrospective cohort study examined the clinical characteristics and treatment modalities used for 468 patients with OSSN from a large tertiary referral center in Gaborone, Botswana, over a 10-year period from 1998 to 2008.

Results. The estimated annual incidence of OSSN in Botswana reached a peak of 7.0 cases per 100000 persons per year in 2004 . The mean age of the patients in the study was 38 years (interquartile range $30-44$ ), and $53.9 \%$ were women. Of the patients, $48.5 \%$ were known to be HIV-infected, $1.5 \%$ were HIV-uninfected, and 50.0\% had unknown HIV status. Among HIV-infected patients with CD4 counts, the median CD4 count was 192 cells/ $\mu \mathrm{L}$. As initial OSSN treatment, $20.7 \%$ of patients received simple surgical excision, $70.9 \%$ received surgical excision with adjunctive beta radiation, $0.9 \%$ received evisceration, $1.3 \%$ received enucleation, and $6.2 \%$ underwent surgical removal of unknown type. The overall rate of known recurrence was $7.1 \%$; however, among those with at least 6 months of follow-up, the recurrence rate was $24.2 \%$. Rates of known recurrence after simple surgical excision and surgical excision with adjunctive beta-radiation were $10.3 \%$ and $5.4 \%$, respectively. Conclusion. This study confirms the high incidence of OSSN among young individuals in Botswana. Further investigation is warranted to determine the most effective treatment modalities to prevent recurrence of OSSN among patients in sub-Saharan Africa.

S Afr Med J 2015;105(5):389-383. DOI:10.7196/SAMJ.8524
\end{abstract}

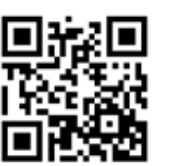

Conjunctival intraepithelial neoplasia (CIN), characterised by dysplasia involving a partial to full thickness of the epithelium, and invasive squamous cell carcinoma (SCC) of the conjunctiva belong to a single disease spectrum termed ocular surface squamous neoplasia (OSSN). ${ }^{[1]}$ In Western countries, OSSN was long regarded as a relatively rare, slow-growing tumour primarily affecting elderly men, ${ }^{[2,3]}$ but recent evidence suggests a 12 -fold increased risk among patients with advanced HIV disease in the USA. ${ }^{[4,5]}$ In sub-Saharan Africa (SSA), the incidence of OSSN has increased exponentially in recent years, and it is now the most common malignancy of the ocular surface in this region. ${ }^{[6]}$ Moreover, relative to OSSN in Western countries, OSSN in SSA is more aggressive and affects younger individuals, who are typically females in the $3 \mathrm{rd}$ and 4 th decades of life. ${ }^{[7-9]}$ The rising incidence has been attributed to the HIV epidemic, as the majority of African individuals affected are HIV-infected. ${ }^{[5,10,11]}$ Ultraviolet $B$ radiation ${ }^{[12,13]}$ and human papillomavirus (HPV) ${ }^{[14,15]}$ have also been implicated in the pathogenesis of OSSN in this region. Surgical excision is the mainstay of treatment for OSSN, ${ }^{[16]}$ but recurrence rates following excision remain unacceptably high, ranging from $15 \%$ to $52 \%{ }^{[1]}$ In an effort to reduce recurrence rates, primary excision has been combined with various adjunctive therapies, including cryotherapy, chemotherapy and radiotherapy ${ }^{[17]}$ The present study describes the clinical characteristics, treatment modalities and preliminary outcomes among OSSN patients at a tertiary referral hospital in Gaborone, Botswana, a country with a population HIV seroprevalence of $17.1 \%{ }^{[18]}$

\section{Methods}

This retrospective cohort study included consecutive patients with OSSN presenting to Princess Marina Hospital (PMH), a tertiary hospital in Gaborone, Botswana, between 1 February 1998 and 31 March 2008. PMH is the ophthalmology referral centre for the southern half of Botswana, treating almost $50 \%$ of all surgical ocular conditions in the country, including OSSN. The standard of care at PMH during the study period was as follows. Patients with a clinical diagnosis of OSSN determined by an ophthalmologist in the eye clinic were scheduled for surgical excision. Surgical excision specimens were sent to the pathology division of the National Health Laboratory of Botswana for diagnosis by a clinical pathologist. All OSSN patients treated during the study period received surgical excision. Adjunctive beta radiation applied during and following surgery was introduced, and became standard of care, in 2002. The source for beta radiation was strontium 90. Beta radiation at a dose of 6000 centigray (cGy) was applied with an oval disc applicator to the base and margins of the excision site at the time of surgery, and was then given weekly at the same dose for 6 weeks. Patients were treated free of charge.

For the present study, patients with a diagnosis of OSSN were identified from existing surgical records as well as from pathology laboratory records. Patient characteristics and surgery-related data were collected, including age, sex, affected eye, date of surgical excision, 
clinical diagnosis and histological diagnosis. Primary treatment modality was determined either from surgery records in cases where a special surgery was used (e.g. evisceration, enucleation) or based on the date of surgical excision of OSSN. The first cohort included patients who received simple surgical excision for OSSN during the time period 1 February 1998 - 31 December 2001. The second cohort included patients who received excision with adjunctive beta radiation during the time period 1 January 2003 - 31 March 2008. Patients treated during the year 2002 were not included in either cohort, as it could not be determined whether these patients received adjunctive beta radiation or not. Patients were categorised as having CIN/dysplasia or invasive SCC of the conjunctiva based on the histological diagnosis from the pathology laboratory records. Duration of follow-up was based on visits to the ophthalmology clinic determined from the clinic's records. HIV-related variables, including CD4 count, viral load and highly active antiviral therapy (HAART) status, were collected from Meditech, the computerised medical record system in place at PMH since 2004. Recurrence was defined as a repeat diagnosis of OSSN in the same eye after treatment of OSSN with surgical excision. We continued to monitor for recurrences in the pathology and surgery records through to 31 March 2009, all study patients being followed up for recurrences for a minimum of 12 months. Given that $\mathrm{PMH}$ is the ophthalmology referral centre for the southern half of Botswana, the estimated annual incidence of OSSN was calculated using half of the population of Botswana as the at-risk population. Sensitivity analyses were performed varying the proportion of the population treated at $\mathrm{PMH}$ from $25 \%$ to $75 \%$ to determine an upper and lower limit of the annual incidence estimate. The total population of Botswana according to the World Bank was used for these calculations. ${ }^{[19]}$

Statistical analyses were performed using STATA version 9.1 (USA). The study was approved by the Health Research and Development Committee of Botswana's Ministry of Health as well as the institutional review boards at PMH and the University of Pennsylvania.

\section{Results}

During the 10-year period 1998 - 2007, 468 patients were treated for OSSN by surgical excision at PMH. The estimated annual incidence of OSSN in Botswana increased over the study period from 2.6 (range 1.0 - 5.3) cases per 100000 persons in 1998 to a peak of 7.0 (range 4.7 - 14.0) per 100000 in 2004 (Fig. 1). The demographics

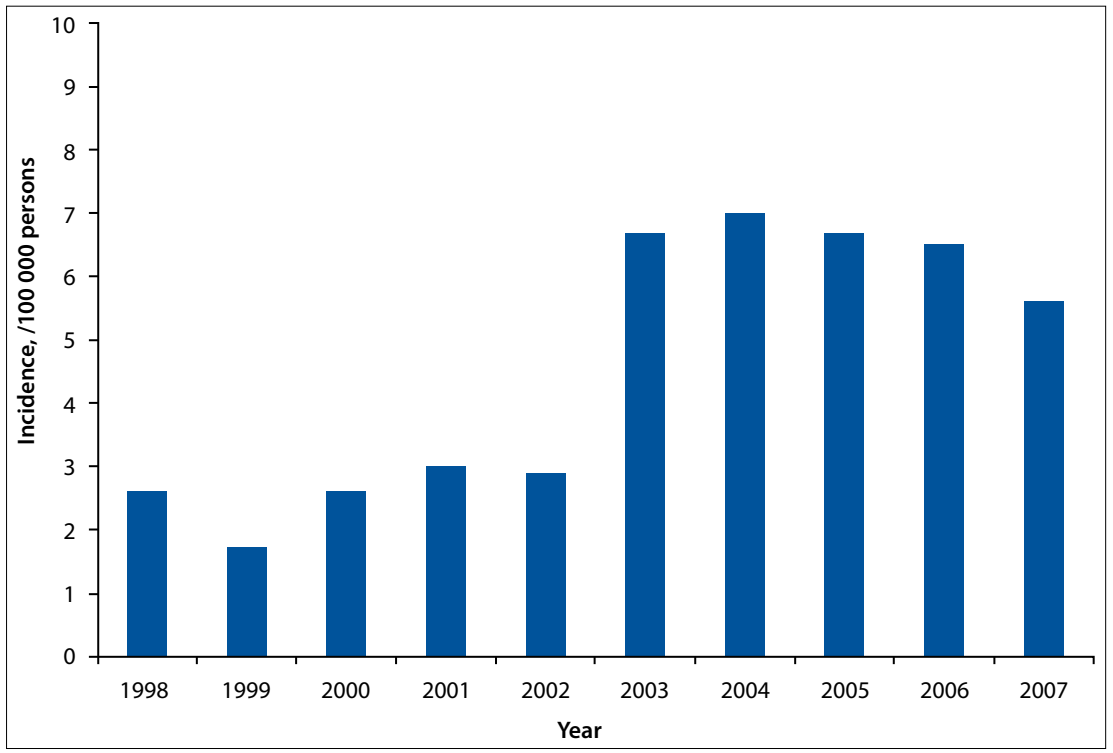

Fig. 1. Estimated annual incidence of OSSN per 100000 persons in Botswana, 1998 - 2007.

and baseline clinical characteristics of the study population as well as the treatment modalities used are presented in Table 1 . The mean age of the patients in the study was 38 years (interquartile range (IQR) 30 - 44), and the majority (53.9\%) were women.

The HIV status and median CD4 count of patients in the study are presented in Table 1. Of the 180 (38.5\%) HIV-infected patients who had CD4 counts available during the study period, 85 (47.2\%) had CD4 counts $<200$ cells $/ \mu \mathrm{L}$ and $152(84.4 \%)$ had CD4 counts $<400$ cells $/ \mu \mathrm{L}$. Forty-three of the 150 patients $(28.7 \%)$ with viral loads available had unsuppressed viral loads ( $>1000$ copies/ $\mathrm{mL}$ ). Of the 85 patients with CD4 counts $<200$ cells $/ \mu \mathrm{L}$ at any time during the study period (who would have been eligible for free HAART according to Botswana's HIV guidelines at the time), $17(20.0 \%)$ were on HAART prior to OSSN surgery, 13 (15.3\%) were initiated on HAART within 1 year after surgery, $9(10.6 \%)$ were initiated on HAART later in the study period, and $46(54.1 \%)$ had no evidence of HAART initiation during the study period.

Five of the 7 (71.4\%) confirmed HIVuninfected patients were under the age of 45 , and $6(85.7 \%)$ were female. Two of the HIV-uninfected patients were diagnosed with CIN/dysplasia and 1 with SCC, and 4 had no histological diagnosis available. All HIV-uninfected patients were treated with adjunctive beta radiation, and none experienced recurrences during the study period.

Of all 468 patients, 33 (7.1\%) experienced known recurrences during the study period. Baseline clinical characteristics and initial treatments of patients who experienced recurrences are presented in Table 1 and data pertaining to timing and treatment of recurrences in Table 2. The mean age of patients who experienced recurrences was 36 years (IQR 29 - 41), and 20 of the 33 patients $(60.6 \%)$ who experienced recurrences were women. The median time to recurrence was 6 months (IQR 2 - 17).

Only approximately half of the study patients $(n=247,52.7 \%)$ had documented ophthalmology clinic follow-up (mean duration of follow-up 13 months, IQR 1 - 21 months) and only 95 patients (20.3\%) had at least 6 months of follow-up. Among patients with at least 6 months of follow-up, 23 $(24.2 \%)$ had one or more recurrences. While 10 of 97 patients $(10.3 \%)$ treated with surgical excision alone and 18 of 332 (5.4\%) treated with adjunctive beta radiation experienced recurrences, the actual recurrence rates in this population are therefore probably higher.

\section{Discussion}

This study of OSSN patients in Botswana contributes to the growing literature documenting the rising incidence of OSSN in SSA and its association with the HIV epidemic. The estimated annual incidence of OSSN in Botswana has risen from 0.13 (range 0.09 - 0.27) cases per 100000 persons in $1993^{[20]}$ to a peak of 7.6 (range 5.0 15.1) per 100000 in 2004. This estimated incidence rate, which may be an underrepresentation of the true incidence rate, is high even for SSA, as estimated incidences of OSSN from other countries in the region are 2.2/100 000 persons in Tanzania and 2.1/100 000 in Uganda. ${ }^{[21,22]}$ These differences in OSSN incidence may reflect differences in HIV prevalence; Botswana has an estimated adult HIV prevalence of $23.0 \%$, whereas the estimated adult HIV prevalences in Tanzania 
Table 1. Characteristics of patients treated for OSSN at PMH, February 1998 - March 2008

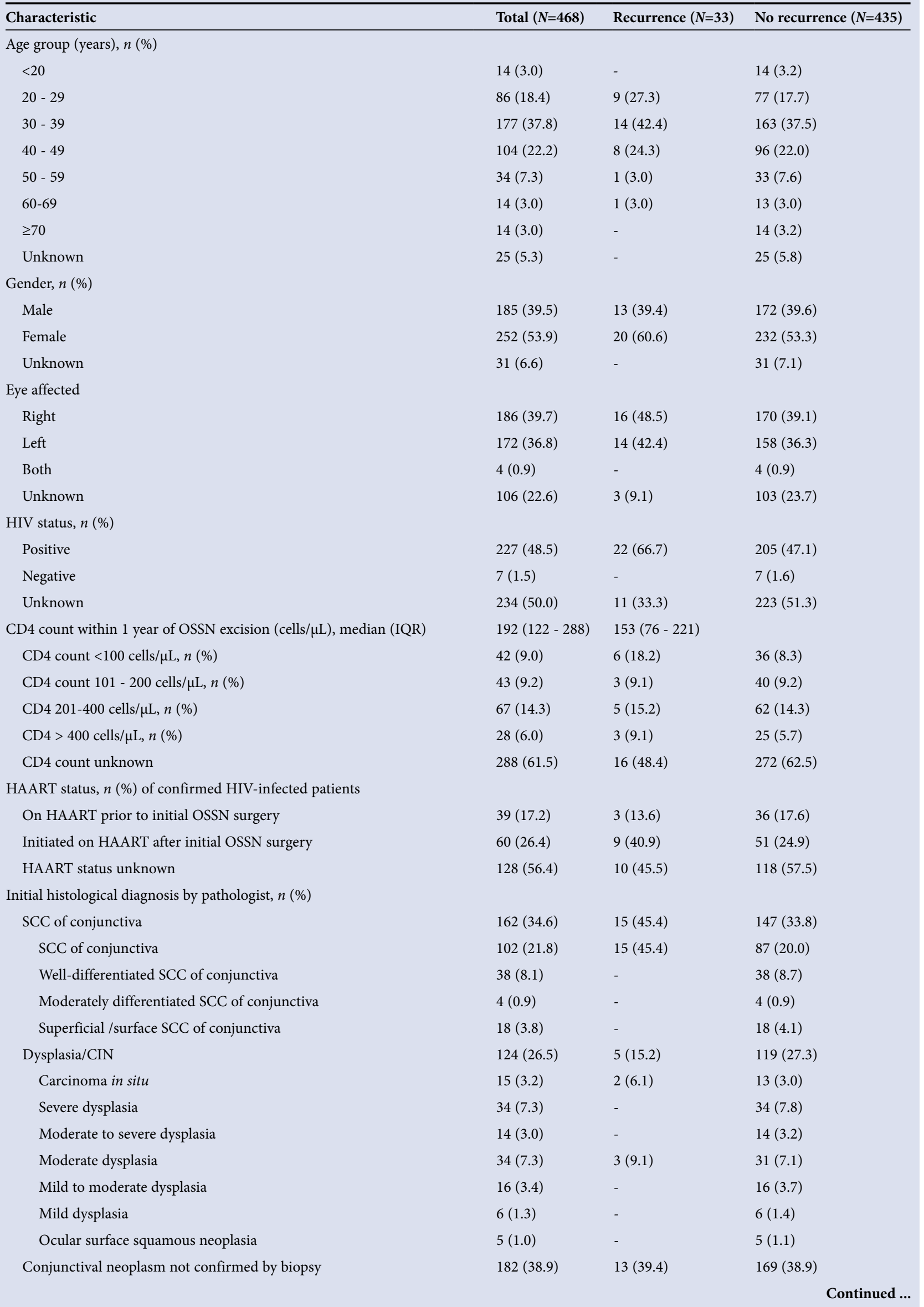


Table 1. (continued) Characteristics of patients treated for OSSN at PMH, February 1998 - March 2008

\begin{tabular}{|c|c|c|c|}
\hline Characteristic & Total $(N=468)$ & Recurrence $(N=33)$ & No recurrence $(N=435)$ \\
\hline \multicolumn{4}{|l|}{ Initial OSSN surgery, $n(\%)$} \\
\hline Simple excision & $97(20.7)$ & $10(30.3)$ & $87(20.0)$ \\
\hline Excision + adjunctive beta radiation & $332(70.9)$ & $18(54.6)$ & $314(72.2)$ \\
\hline Evisceration & $4(0.9)$ & $1(3.0)$ & $3(0.7)$ \\
\hline Enucleation/eye removal & $6(1.3)$ & $1(3.0)$ & $5(1.1)$ \\
\hline Unknown surgery (during year 2002) & $29(6.2)$ & $3(9.1)$ & $26(6.0)$ \\
\hline
\end{tabular}

\begin{tabular}{ll} 
Table 2. Recurrences among OSSN patients $(\boldsymbol{N}=\mathbf{3 3})$ & treated at \\
PMH, 1998 - 2008 & $\boldsymbol{n}(\%)$ \\
\hline Characteristic & \\
\hline OSSN recurrences per patient & $26(78.8)$ \\
1 & $5(15.2)$ \\
2 & $1(3.0)$ \\
3 & $1(3.0)$ \\
5 & \\
Time to first OSSN recurrence (years) & $22(66.7)$ \\
$<1$ & $9(27.3)$ \\
$1-2$ & $2(6.0)$ \\
$2-3$ & \\
Treatment of OSSN recurrence & $8(18.2)$ \\
Simple excision & $30(68.2)$ \\
Excision + adjunctive beta radiation & $3(6.8)$ \\
Evisceration & $3(6.8)$ \\
Enucleation/eye removal &
\end{tabular}

and Uganda are $5.1 \%$ and $7.2 \%$, respectively. ${ }^{[23,24]}$ In accordance with the assertion that the rising incidence of OSSN in African countries is related to the HIV epidemic, studies from this region have reported high rates of HIV seropositivity among OSSN patients, ranging from $71 \%$ to $92 \% .{ }^{[25-27]}$ In the present study, $97.0 \%$ of patients with HIV tests available were HIV seropositive, though HIV status was unknown for $50.0 \%$ of patients in the study. Alternatively, the rising incidence of OSSN may be related in part to increased rates of detection of OSSN over time.

In keeping with previous studies from Africa, ${ }^{[2,21]}$ the majority of OSSN patients in Botswana were in the 3rd, 4th or 5th decade of life. The mean age of OSSN patients in our Botswana patient population was 38 years, comparable to mean ages of 38.7 years and 37.7 years in studies from Tanzania and Zimbabwe, respectively. ${ }^{[26,28]}$ Interestingly, the present study and several previous studies from SSA found that HIV-uninfected patients who developed OSSN were not significantly older than those infected with HIV, suggesting that other causes independent of HIV infection, such as ultraviolet light or HPV infection, may play a role in the pathogenesis of OSSN among young Africans. ${ }^{[8,26,27]}$ In the present study, OSSN displayed a slight female predominance, which has been reported in several other SSA studies. ${ }^{[21,25]}$ The female predominance of OSSN in this region may reflect the higher HIV prevalence in women relative to men, which is certainly the case in Botswana $(19.8 \%$ v. $13.9 \%) .{ }^{[18]}$ In addition to affecting younger, mostly female, individuals in Africa, OSSN has been reported to be a more rapidly growing, aggressive tumour among
SSA populations. ${ }^{[7]}$ In support of this, 16 patients in the present study had invasive tumours that ultimately required evisceration $(n=7)$ or enucleation $(n=9)$, resulting in loss of the affected eye.

Emerging evidence suggests that OSSN may be an AIDSdefining illness among patients in SSA. In the present study, the median CD4 count within 1 year of OSSN surgery was 192 cells/ $\mu \mathrm{L}$ (IQR 122 - 288), and more than half of the OSSN patients had CD4 counts $<200$ cells/ $\mu \mathrm{L}$, consistent with a diagnosis of AIDS. A recent study from Tanzania reported that $85 \%$ of OSSN patients had CD4 counts $<200$ cells $/ \mu \mathrm{L}$, and the median CD4 count of patients at the time of presentation was 71 cells $/ \mu \mathrm{L}^{\left[{ }^{[25]}\right.}$ Similarly, in Uganda the median CD4 count among HIV-infected OSSN patients was 111 cells $/ \mu \mathrm{L}$ (IQR $62-221$ ), and $65 \%$ of HIV-infected OSSN patients died of AIDS-related complications at a median of 20 months after OSSN diagnosis..$^{[8]}$ Despite the fact that many patients have advanced HIV disease at OSSN diagnosis, evidence suggests that OSSN may be the first clinical manifestation of HIV infection in the majority of patients, and that patients may often be unaware of their HIV status at presentation with OSSN. ${ }^{[27,29]}$ Together, these findings highlight the critical role of eye clinics in conducting HIV testing and referring patients for CD4 monitoring and HAART initiation, if appropriate. Given the high percentage of OSSN patients who are not only HIVinfected but also have advanced HIV disease, this is likely to be a high-yield method of identifying patients who are eligible and would benefit from lifesaving HAART therapy but would otherwise not have been initiated on HAART because they have no other clinical manifestations of HIV infection.

Simple surgical excision is the mainstay of treatment for OSSN in Africa, ${ }^{[10]}$ yet few studies have examined the efficacy of simple surgical excision for the prevention of recurrences in African populations. High rates of recurrence $(16.6 \%, 31.2 \%)$ have been reported following surgical excision of OSSN in Tanzania and Kenya. ${ }^{[25,30]}$ However, a countrywide study in Uganda reported a recurrence rate of $3.2 \%$ among OSSN patients treated with simple surgical excision with a median follow-up of 32 months, ${ }^{[8]}$ suggesting that surgical excision alone may provide adequate prevention of recurrence if proper removal technique is employed. In the present study, we found an overall recurrence rate of $7.1 \%$ among OSSN patients in Botswana, but in patients with at least 6 months of follow-up, the rate increased to $24.2 \%$. Our recurrence rate calculations are certainly limited given that follow-up data were not available for about half of the patients. As a result, we may have missed some patients who experienced recurrences because they failed to return to the eye clinic (e.g. because they died, sought treatment in the private sector, moved to another region or chose not to seek Western medical treatment despite clinically significant symptoms). In addition, the lack of data on other confounding variables, such as surgical margins, limits our ability to compare these two interventions statistically. However, the present data indicate that at least 1 in 10 patients who received simple 
surgical excision experienced a recurrence, suggesting that adjunctive therapies may be needed to control recurrences adequately in this HIV-infected African population. Whether adjunctive beta radiation is an effective alternative is unclear from this dataset, but the results suggest that further investigation is needed.

\section{Conclusion}

This study of OSSN patients from Botswana affirms the rising incidence of OSSN in association with the HIV epidemic. Further research is warranted to determine whether surgical excision alone is sufficient to prevent recurrences in this population, or whether adjunctive therapy is required. The finding that young HIV-negative women are also affected by OSSN in SSA also warrants further investigation as to whether the epidemiology of OSSN is changing even outside of the HIV epidemic.

\section{References}

1. Lee GA, Hirst LW. Ocular surface squamous neoplasia. Surv Ophthalmol 1995;39(6):429-450. [http:// dx.doi.org/10.1016/S0039-6257(05)80054-2]

2. Lee GA, Hirst LW. Retrospective study of ocular surface squamous neoplasia. Aust N Z J Ophthalmol 1997;25(4):269-276. [http://dx.doi.org/10.1111/j.1442-9071.1997.tb01514.x]

3. McKelvie PA, Daniell M, McNab A, Loughnan M, Santamaria JD. Squamous cell carcinoma of the conjunctiva: A series of 26 cases. Br J Ophthalmol 2002;86(2):168-173. [http://dx.doi.org/10.1136/ bjo.86.2.168

4. Guech-Ongey M, Engels ES, Goedert JJ, Biggar RJ, Mbulaiteye SM. Elevated risk for squamous cell carcinoma of the conjunctiva among adults with AIDS in the United States. Int J Cancer 2008;122(11):2590-2593. [http://dx.doi.org/10.1002/ijc.23384]

5. Karcioglu ZA, Wagoner MD. Demographics, etiology, and behavior of conjunctival squamous cell carcinoma in the 21st century. Ophthalmology 2009;116(11):2045-2046. [http://dx.doi.org/10.1016/j. ophtha.2009.09.031]

6. Ateenyi-Agaba C Conjunctival squamous cell carcinoma associated with HIV infection in Kampala, 6. Ateenyi-Agaba C. Conjunctival squamous cell carcinoma associated with HIV infection in Ka
Uganda. Lancet 1995;345(8951):695-696. [http://dx.doi.org/10.1016/S0140-6736(95)90870-6]

7. Poole TR. Conjunctival squamous cell carcinoma in Tanzania. Br J Ophthalmol 1999;83(2):177-179. Poole TR. Conjunctival squamous cell carcin
[http://dx.doi.org/10.1136/bjo.83.2.177]

[http://dx.doi.org/10.1136/bjo.83.2.177]
8. Waddell KM, Downing RG, Lucas SB, Newton R. Corneo-conjunctival carcinoma in Uganda. Eye 8. Waddell KM, Downing RG, Lucas SB, Newton R. Corneo-con
2006;20(8):893-899. [http://dx.doi.org/10.1038/s.eye.6702043]

2006;20(8):893-899. [http://dx.doi.org/10.1038/sj.eye.6702043]
9ola EC, Masanganise R. Rusakaniko S. The trend of ocular surface squamous neoplasia among oculat 9. Pola EC, Masanganise R, Rusakaniko S. The trend of ocular surface squamous neoplasia among ocula
surface tumour biopsies submitted for histology from Sekuru Kaguvi Eye Unit, Harare between 1996 surface tumour biopsies submitted for histo

0. Sasco AJ, Jaquet A, Boidin E, et al. The challenge of AIDS-related malignancies in sub-Saharan Africa. PLoS One 2010;5(1):e8621. [http://dx.doi.org/10.1371/journal.pone.0008621]

11. Nkomazana O, Tshitswana D. Ocular complications of HIV infection in sub-Sahara Africa. Curr HIV / AIDS Rep 2008;5(3):120-125. [http://dx.doi.org/10.1007/s11904-008-0019-z]

12. Ateenyi-Agaba C, Dai M, Le Calvez F, et al. TP53 mutations in squamous carcinomas of the conjunctiva: Evidence for UV-induced mutagenesis. Mutagenesis 2004;19(5):399-401. [http://dx.doi. org/10.1093/mutage/geh048]
13. Newton R, Ferlay J, Reeves G, et al. Effect of ambient solar ultraviolet radiation on incidence of squamous-cell carcinoma of the eye. Lancet 1996;347(9013):1450-1451. [http://dx.doi.org/10.1016/ S0140-6736(96)91685-2]

14. Tornesello ML, Duraturo ML, Waddell KM, et al. Evaluating the role of human papillomaviruses in conjunctival neoplasia. Br J Cancer 2006;94(3):446-449. [http://dx.doi.org/10.1038/sj.bjc.6602921]
c.

15. Simbiri KO, Murakami M, Feldman M, et al. Multiple oncogenic viruses identified in ocular surface squamo 5. Simbiri KO, Murakami M, Feldman M, et al. Multiple oncogenic viruses identified in ocular surface squ
neoplasia in HIV-1 patients. Infect Agent Cancer 2010;5:6. [http://dx.doi.org/10.1186/1750-9378-5-6]

16. Shields JA, Shields CL, De Potter P. Surgical management of conjunctival tumors. The 1994 Lynn B. McMahan Lecture. Arch Ophthalmol 1997;115(6):808-815. [http://dx.doi.org/10.1001/ archopht.1997.01100150810025]

17. Gichuhi S, Irlam JJ. Interventions for squamous cell carcinoma of the conjunctiva in HIV-infected individuals. Cochrane Database Syst Rev 2007;2:CD005643. [http://dx.doi.org/10.1002/14651858. CD005643.pub3]

18. National AIDS Coordinating Agency, United Nations, The African Comprehensive HIV/AIDS Partnership, Central Statistics Office. Botswana AIDS Impact Survey II: Popular Report. New York: United Nations, 2005. http://www.unbotswana.org.bw/undp/documents/final_popular_report_feb06. pdf (accessed 5 October 2012).

19. World Bank. The World Bank Data: Population, Total. Washington: World Bank, 2012. http://data. worldbank.org/indicator/SP.POP.TOTL (accessed 5 October 2012)

20. Semo B, Bisson G, Nkomazana O. Ocular surface squamous neoplasia in HIV-infected patients in Botswana: An AIDS-defining illness? Presented at the 8th International Conference on Malignancies in AIDS and other Immunodeficiencies, 29-30 April 2004, Bethesda, MD, USA.

21. Furahini G, Lewallen S. Epidemiology and management of ocular surface squamous neoplasia in Tanzania. Ophthalmic Epidemiol 2010;17(3):171-176. [http://dx.doi.org/10.3109/09286581003731544]

22. Parkin DM, Wabinga H, Nambooze S, Wabwire-Mangen F. AIDS-related cancers in Africa: Maturation of the epidemic in Uganda. AIDS 1999(18):2563-2570. [http://dx.doi.org/10.1097/00002030199912240-00010

23. Joint United Nations Programme on HIV/AIDS (UNAIDS). Global report: UNAIDS report on the global AIDS epidemic 2013. http://www.unaids.org/sites/default/files/en/media/unaids/contentassets/ documents/epidemiology/2013/gr2013/UNAIDS_Global_Report_2013_en.pdf） (accessed 10 November 2014).

24. Tanzania Commission for AIDS (TACAIDS), Zanzibar AIDS Commission (ZAC), National Bureau of Statistics (NBS), Office of the Chief Government Statistician (OCGS), and ICF International 2013. Tanzania HIV/AIDS and Malaria Indicator Survey 2011-12. Dar es Salaam, Tanzania: TACAIDS, ZAC, BS, OCGS, and ICF International, March 2013.

25. Waddell KM, Lewallen S, Lucas SB, et al. Carcinoma of the conjunctiva and HIV infection in Uganda and Malawi. Br J Ophthalmol 1996;80(6):503-508. [http://dx.doi.org/10.1136/bjo.80.6.503]

26. Porges Y, Groisman GM. Prevalence of HIV with conjunctival squamous cell neoplasia in an African provincial hospital. Cornea 2003;22(1):1-4. [http://dx.doi.org/10.1097/00003226-200301000-00001]

27. Spitzer MS, Batumba NH, Chirambo T, et al. Ocular surface squamous neoplasia as the first apparent manifestation of HIV infection in Malawi. Clinical and Experimental Ophthalmology 2008;36(5):422425. [http://dx.doi.org/10.1111/j.1442-9071.2008.01794.x]

28. Makupa II, Swai B, Makupa WU, White VA, Lewallen S. Clinical factors associated with malignancy and HIV status in patients with ocular surface squamous neoplasia at Kilimanjaro Christian Medical Centre, Tanzania. Br J Ophthalmol 2012;96(4):482-484. [http://dx.doi.org/10.1136/ bjophthalmol-2011-300485

29. Pradeep TG, Gangasagara SB, Subbaramaiah GB, Suresh MB, Gangashettappa N, Durgappa R. Prevalence of undiagnosed HIV infection in patients with ocular surface squamous neoplasia in a tertiary center in Karnataka, South India. Cornea 2012;31(11):1282-1284. [http://dx.doi.org/10.1097/ ICO.0b013e3182479aed]

30. Chisi SK, Kollmann MK, Karimurio J. Conjunctival squamous cell carcinoma in patients with human immunodeficiency virus infection seen at two hospitals in Kenya. East Afr Med J 2006;83(5):267-270. [http://dx.doi.org/10.4314/eamj.v83i5.9432]

Accepted 18 March 2015 